\title{
Drug Technology in Hunting Practice
}

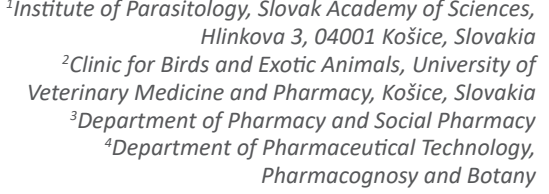

Received 15 June, 2021, accepted 17 June, 2021

Abstract Antiparasitic therapy in living ratites is based on the right dose and efficacy is only when the drug is pharmaceutically stable and safe. Ivermectin is considered to be the most widely used drug in the treatment of parasitosis in ruminants worlwide. For these reasons, in our study, we focused on the pharmaceutical investigation of ivermectin by SEM analysis of its powder particle shape and size, flow properties of solids (angle of repose, compressibility index, Hausner ratio) and zeta potential.

\section{INTRODUCTION}

Frequent occurrence of wild and domestic ruminants together on common pastures raises the question about the role of wild species in the transmission of gastrointestinal (GI) nematodes between small ruminants. The similar feeding habits of wild and domestic ruminants may represent a high potential risk for the transmission of Gl nematodes from wild to domestic sheep and goats. Hunters are required to estimate the total number of animals and their total weights in hunting districts. The distribution of drugs in the feed may thus be easily inconsistent, so the drugs may be underdosed. Underdosing is one of the most common managerial flaws contributing to the development of anthelmintic resistance (AR) (TorresAcosta and Hoste, 2008). Ivermectin (IVM) is one of the best known and most widely used antiparasitic drugs in human and veterinary medicine. IVM is a semi-synthetic product obtained from avermectin, naturally synthesised by the microorganism Streptomyces avermitilis. It consists of a mixture of two homologues, dihydroavermectin $\mathrm{B}_{1 \mathrm{a}}\left(\mathrm{H}_{2} \mathrm{~B}_{1 \mathrm{a}}\right)$ and dihydroavermectin $\mathrm{B}_{1 \mathrm{~b}}\left(\mathrm{H}_{2} \mathrm{~B}_{1 \mathrm{~b}}\right)$ (Cerkvenik et al., 2001). The aim of our study was to analyse two samples of Galmectin premix stored at different temperatures and humidity for 1 month using scanning electron microscope (SEM) analyses and flow properties, in order to determine the effect of the external environment on the structure of the premix.

\section{MATERIALS AND METHODS}

Chemicals: IVM in Galmectin $0.150 \mathrm{mg} / \mathrm{g}$ premix (PHARMAGAL Ltd., Nitra, Slovakia)

\section{Data treatment}

Sample No. 1 was stored at $20^{\circ} \mathrm{C}, 58 \%$ humidity in a glass vessel and sample No. 2 was stored at $4.2^{\circ} \mathrm{C}, 75 \%$ humidity in a glass vessel. Samples of the premix (Sample No. 1 and Sample No. 2) for SEM analysis (MIRA3, TESCAN) were observed in the dried state. We placed them on a base plate with a size of about $1 \mathrm{~cm}^{2}$. According to Kostelanská recommendations (2017), the samples should be coated with a layer of metal with good thermal and electrical conductivity (gold, silver, platinum, carbon or an alloy of platinum and palladium) before observation. In this case, we used a layer of carbon (about 20 $\mathrm{nm})$, which we applied using a sputtering device. The carbon layer provided the samples with a negative charge and a heat circuit in which most of the energy of the accelerated primary electrons was converted. The prepared premix samples were placed in a chamber placed in the lower part of the microscope tube. Samples of the premix were placed on a trigonometric table, near which detectors of individual signals (secondary and reflected electrons) were placed.

Compressibility index is a measure of strength and stability, and Hausner ratio is a measure of the interparticulate friction. 
Flow character is rated based on compressibility index and Hausner ratio.

Compressibility index $=100\left(\mathrm{~V}_{0}-\mathrm{V}_{\mathrm{f}}\right) / \mathrm{V}_{0}$ Hausner ratio $=\mathrm{V}_{\mathrm{o}} / \mathrm{V}_{\mathrm{f}}$

where: $V_{0}=$ original bulk volume of powder; $V_{f}=$ final tapped volume of powder.

Zeta potential measurement was performed using ZetaSizer ZS device, working on the principle of laser Doppler velocimetry (LDV) in combination with Dynamic Light Scattering (DLS). After switching on, the instrument was calibrated and heated to a measuring temperature of $25^{\circ} \mathrm{C}$. First, the sample was dispersed in $100 \mathrm{ml}$ of distilled water. Then we transferred the solution to the measuring cuvette with a syringe. We used the configuration of the signal passed through the sample. The device automatically evaluated the standard deviation and displayed it together with the zeta potential value in the software program.

\section{RESULTS AND DISCUSSION}

SEM analysis of the particle shape of sample No. 1 stored at 20 ${ }^{\circ} \mathrm{C}, 58 \%$ humidity in a glass vessel revealed an angular particle shape at $500 \times$ magnification. Particles with a smooth surface and a regular shape had better flow properties than squareshaped particles that fit together. We confirmed this fact at a magnification of 3,000 times, where we found that the individual particles of the examined sample really fit into each other. At 8,000 and 20,000 times magnification, we confirmed the angular, irregular shape of the particles and also observed small particles on the surface of larger particles.

When comparing the SEM analysis of the particle shape of sample No. 1 and sample No. 2 at 500x magnification, it is clear that in the case of sample No. 2, the individual particles were compacted under the influence of moisture. At 500x magnification of sample No. 2, we could clearly see that the space between the particles had shrunk and they tended to clump together. At 3,000 $\times$ magnification, we found a more rounded shape of the particles of sample No. 2 .

The second part of the SEM analysis was the measurement of individual particles. We measured the particles at 1,500 and 4,000 fold magnification. In sample No. 1, we measured a total of 24 randomly selected particles. The average particle size was $12.24 \mu \mathrm{m}$. On evaluating the SEM analysis of the particle size of sample No. 2 at 1,500 $\times$ magnification, we also observed isolated agglomerates of 42.16 and $39.30 \mu \mathrm{m}$. As with sample No. 1, we selected 24 particles at 1,500 and 4,000 fold magnification. The average size of the individual particles was $12.65 \mu \mathrm{m}$. According to our calculations, the compressibility index values ranged from $2.85 \%$ to $7.69 \%$, which means that the nature of the flow of sample No. 1 was excellent. The Hausner ratio values ranged from 1.02 to 1.08 , which again confirms the result of the compressibility index calculation. This result shows that in the case of storage conditions (temperature $20^{\circ} \mathrm{C}$, humidity $58 \%$ ), the flow properties of the premix do not deteriorate. The compressibility index values of sample No. 2 ranged from $2.98 \%$ to $5.00 \%$, which resulted in an excellent flow pattern of the sample. The Hausner ratio values ranged from 1.03 to 1.05 , which also indicates the excellent nature of the flow of the examined sample No. 2 .

Angle of repose measurement results ${ }^{\circ} \pm$ SD of sample No. 1 and sample No. 2 were repeated three times for each sample. According to the generally accepted Carr scale, powder with a pour angle below $30^{\circ}$ has good flowability, $30^{\circ}-45^{\circ}$ shows some cohesiveness, $45^{\circ}-55^{\circ}$ shows real cohesiveness and powder with a pour angle above $55^{\circ}$ is characterised by very high cohesiveness and very limited flowability. It follows from the above that the samples examined by us had a pour angle in the range of $30^{\circ}-45^{\circ}$ and showed certain coherence.

The Zeta potential of both Galmectin $0.150 \mathrm{mg} / \mathrm{g}$ premix powder samples examined was measured using a ZetaSizer (Malvern, UK), which recorded the results, and these were subsequently processed into Zeta potential distribution and electrophoretic mobility distribution. When evaluating the results of the analysis, we assumed that if the Zeta potential was in the range of -30 to $+30 \mathrm{mV}$, then the charge on the surface was too small to prevent contact and the particles tended to agglomerate. The measurement was performed in three cycles, each cycle containing 10 measurements for 10 seconds. The resulting Zeta potential measurement was created as the average of all measurements. The instrument recorded one peak in both cases. Zeta potential of sample No. 1 was $-18.7 \pm 6.27 \mathrm{mV}$, so it tended to clump. Zeta potential of sample No. 2 had a value of $-17.2 \pm 9.22 \mathrm{mV}$, which showed that similar to sample No. 1, sample No. 2 also tended to clump. Differences in the measured values of Zeta potential of sample No. 1 and sample No. 2 were insignificant, indicating that the effect of external conditions did not affect the stability of the samples.

.The effect of moisture on the powder shape was determined from the SEM analysis. The sample which was exposed to moisture showed a more rounded shape and also the formation of agglomerates. Based on the obtained results of the pharmaceutical analysis, we propose that in hunting practice, premixes have to be stored in well-sealed bags that protect against the effects of moisture.

\section{ACKNOWLEDGEMENT}

This study was supported by funds from the Scientific Grant Agency VEGA 2/0099/19.

\section{CONFLICT OF INTEREST STATEMENT}

The authors declare that they have no conflicts of interest. 
References

[1] Cerkvenik V, Doganoc DZ, Skubic V, Beek WMJ, Keukens HJ. Thermal and long-term freezing stability of ivermectin residues in sheep milk. Eur Food Res Technol. 2001;213:72-6.

[2] Kostelanská K, Gajdziok, J. Elektrónová mikroskopie pro předmět Instrumentální analytické metody ve farmaceutické technologii. Brno: 2017.

[3] Torres-Acosta JFJ, Hoste H. Alternative or improved methods to limit gastro-intestinal parasitism in grazing sheep and goats. Small Rum Res. 2008; 77:159-173. 